\title{
Competition in Unit vs. Ad Valorem Taxes
}

Ben Lockwood

Department of Economics and CSGR

CSGR Working Paper No 86/01

June 2001

\begin{abstract}
This note shows that in the Zodrow-Miesowski-Wilson model, the Nash equilibrium in capital taxes depends on whether these taxes are unit (as assumed in the literature) or ad valorem (as in reality). In a symmetric version of the model with Cobb-Douglas technology, public good provision is higher, and residents in both countries are better off, when countries compete in unit taxes.
\end{abstract}

Keywords: tax competition, unit tax, ad valorem tax.

JEL Classification: H20, H25

Address for Correspondence

Professor Ben Lockwood

Department of Economics and CSGR

University of Warwick

Coventry CV4 7AL UK

Email: b.lockwood@warwick.ac.uk 


\section{Non-Technical Summary}

This paper explores one aspect of capital tax competition that has previously received little attention: that is, whether it matters if the taxes are unit or ad valorem. This is an issue because of the fact that in practice, capital and taxes are always ad valorem (i.e. levied on the income from capital), but in the theory, they are always assumed to be unit, or specific (i.e. levied on physical units of capital).

In this paper, we show that this unrealistic simplification is not without loss of generality. Specifically, we show, using the leading model of capital tax competition (the ZodrowMiezowski-Wilson model), that the outcome (Nash equilibrium) in unit capital taxes is generally different to the Nash equilibrium in ad valorem capital taxes, in the sense that at the two equilibria, public good provision and private consumption are generally different. Under certain assumptions, we show that public good provision is lower, and both countries are worse off, when countries compete with ad valorem taxes.

The difference in equilibrium outcomes arises for two reasons. First, the elasticity of the tax base with respect to the tax rate is different with unit and ad valorem taxes, for reasons explained in detail in the next section. Second, in the unit case, in equilibrium, a small increase in the tax rate decreases the post-tax income of domestic residents by the amount of the tax base, but in the ad valorem case, a small increase in the tax rate decreases private income by an amount more than the tax base, as it raises the pre-tax return on capital, and thus the ad valorem tax base itself. 


\section{Introduction}

There is now a substantial theoretical literature on tax competition ${ }^{1}$, covering virtually every kind of tax where the tax base may possibly be mobile between jurisdictions (capital income taxes, commodity taxes, corporate taxes, etc). However, one aspect of tax competition that has received virtually no attention so far is whether it matters if the taxes are unit or ad valorem. Indeed, in the leading model of competition over taxes on capital, the Zodrow-MiesowskiWilson model, is always assumed ${ }^{2}$ that the tax is levied per unit of capital (i.e. is a unit tax), whereas in reality, taxes on capital income are always ad valorem (i.e. a proportion of gross income from capital).

It is the purpose of this short paper to show that this unrealistic simplification is not without loss of generality. Specifically, we show, in the context of the Zodrow-Miesowski-Wilson model, that the Nash equilibrium in unit capital taxes is generally different to the Nash equilibrium in ad valorem capital taxes, in the sense that at the two equilibria, public good provision and private consumption are generally different. In particular, in a symmetric version of the model, with Cobb-Douglas production technology, we show that public good provision is lower when countries compete with ad valorem taxes. We also establish a welfare result: residents in both countries are better off when countries compete in unit taxes.

The difference in Nash equilibrium outcomes arises for two reasons. First, the elasticity of the tax base with respect to the tax rate is different with unit and ad valorem taxes, for reasons explained in detail in the next section. Second, in the unit case, in equilibrium, a small increase in the tax rate decreases the post-tax income of domestic residents by the amount of the tax base, but in the ad valorem case, a small increase in the tax rate decreases private income by an amount more than the tax base, as it raises the pre-tax return on capital, and thus the ad valorem tax base itself.

\footnotetext{
${ }^{1}$ See , for example, Wilson(1999) for a survey of the literature, with a focus on capital taxes, and Lockwood(2001) for a synthesis of some models of commodity tax competition.
} 
Perhaps one reason why these points have been missed in the literature is that in the closed economy, or the small open economy, unit and ad valorem taxes on capital are equivalent. However, it is a general principle in game theory that economic instruments that are equivalent for a single decision-maker are not generally equivalent when two or more decision makers interact. The classic example is of course, price and quantity setting by firms: for a monopolist, these two instruments are equivalent, but for two duopolists, they are not. Our results confirm that this kind of non-equivalence also applies to unit and ad valorem taxes.

Our results also relate ${ }^{3}$ to the literature which studies the unit and ad valorem taxes in a single tax jurisdiction with imperfect product market competition. In that setting, under quite general conditions, a revenue-neutral switch from unit to ad valorem taxation causes firms to produce more and thus raises welfare (Wicksell(1896), Suits and Musgrave(1953), Delipalla and Keen(1992)). Such a switch may even be Pareto-improving i.e. raise both consumer surplus, and profit simultaneously (Skeath and Trandel(1994)). Our results show that with multiple competing tax jurisdictions, unit and ad valorem taxes are not equivalent for a different reason, but that in contrast, a switch to unit taxation from ad valorem taxation is Pareto-improving.

\section{The Model and Tax Base Elasticities}

We consider a two-country version of the Zodrow-Miesowski-Wilson model. Each country $\mathrm{i}=1,2$ is populated by $\mathrm{L}_{\mathrm{i}}$ identical residents each of whom supplies one unit of labour, and owns $\mathrm{k}$ units of capital. Capital is mobile between countries, while labour is not. In both countries competitive firms combine capital and labour to produce output: output in country $i$ is $F\left(K_{i}, L_{i}\right)$, where $L_{i}, K_{i}$ are the amounts of labour and capital employed. We assume that both countries are the same size i.e. $\mathrm{L}_{1}=\mathrm{L}_{2}=\mathrm{L}$. We can therefore write the production function for either country in intensive form as $\mathrm{f}\left(\mathrm{k}_{\mathrm{i}}\right)$, where $\mathrm{k}_{\mathrm{i}}=\mathrm{K}_{\mathrm{i}} / \mathrm{L}, \mathrm{i}=1,2$. Finally, let $\mathrm{T}_{1}, \mathrm{~T}_{2}$ be the unit taxes on income from capital,

\footnotetext{
2 For example, Wilson(1986), Zodrow and Miezowski(1986) assume a unit tax, as do well-known subsequent developments of the model by Wildasin(1989), Bucovetsky(1991), and others.

3 The paper most closely related to this one is Lockwood and Wong(2000), where it is shown that unit and ad valorem tariffs give rise to different tariff equilibria in a simple model of international trade. However, there it is shown, at least for the case of symmetric countries, that ad valorem tariffs lead to less trade distortion in Nash equilibrium and thus make both countries better off. So, when considering tax or tariff competition there are clearly no general results on the relative merits of specific and ad valorem taxes.
} 
and let $\mathrm{t}_{1}, \mathrm{t}_{2}$ be the corresponding ad valorem taxes. Both kinds of taxes are assumed to be source-based ${ }^{4}$.

Given taxes, equilibrium in the model is described as follows. Since capital is mobile, the posttax rate of return for the investor in the two countries must be the same with either unit or ad valorem taxes i.e.

$$
f_{1}^{\prime}\left(k_{1}\right)-T_{1}=f_{2}^{\prime}\left(k_{2}\right)-T_{2}
$$

and

$$
f_{1}^{\prime}\left(k_{1}\right)\left(1-t_{1}\right)=f_{2}^{\prime}\left(k_{2}\right)\left(1-t_{2}\right)
$$

Also, as total capital is fixed, the sum of $\mathrm{k}_{1}$ and $\mathrm{k}_{2}$ must equal $2 \mathrm{k}$, where $\mathrm{k}$ is the capital endowment per head in each country:

$$
k_{1}+k_{2}=2 k
$$

So, (1),(3) determine $\mathrm{k}_{1}, \mathrm{k}_{2}$ as functions of the two tax rates in the unit case, and (2),(3) determine $\mathrm{k}_{1}, \mathrm{k}_{2}$ as functions of the two tax rates in the ad valorem case.

We will be interested at the elasticity of the tax base with respect to i's tax rate in the symmetric Nash equilibrium, as this elasticity determines the marginal cost of public funds and therefore public good supply. We proceed by calculating these elasticities for the case where taxes set by both countries (and therefore both capital stocks) are equal: these formulae then apply by definition in symmetric Nash equilibrium.

In the unit case, the tax base is just $\mathrm{k}_{\mathrm{i}}$. Totally differentiating (1) with respect to e.g. $\mathrm{T}_{1}$ and using $d k_{2}=-d k_{1}$ from (3) gives

$$
\frac{d k_{1}}{d T_{1}}=\frac{1}{f^{\prime \prime}\left(k_{1}\right)+f^{\prime \prime}\left(k_{2}\right)}
$$

\footnotetext{
${ }^{4}$ With residence-based taxes, there would be no tax competition, and then unit and ad valorem taxes would be equivalent.
} 
Evaluating (4) at $\mathrm{T}_{1}=\mathrm{T}_{2}$ (so that $\mathrm{k}_{1}=\mathrm{k}_{2}$ ), and rearranging, gives:

$$
\varepsilon_{u}=-\left(\frac{T_{i}}{k_{i}} \frac{d k_{i}}{d T_{i}}{ }_{\substack{T_{1}=T_{2}=T \\ f^{\prime}(k)}}=\frac{1}{\eta},\right.
$$

where $\eta=-\frac{k f^{\prime \prime}(k)}{f^{\prime}(k)}$ is the (absolute) elasticity of the marginal product of capital. So, in any equilibrium where taxes are equal, the elasticity of the tax base with respect to the tax rate is onehalf the ad valorem equivalent of T i.e. $T / f^{\prime}(k)$, times one over the elasticity of the marginal product of capital ${ }^{5}, \eta$.

Now in the ad valorem case, the tax base $b_{i}=f^{\prime}\left(k_{i}\right) k_{i}$. Note that the elasticity of $\mathrm{b}_{\mathrm{i}}$ with respect to $k_{i}$ is $1-\eta$, where $\eta$ is defined as before. Intuitively, this is because an increase in $k_{i}$ increases $b_{i}$ directly, but also reduces $f^{\prime}\left(k_{i}\right)$, which has a negative effect on $b_{i}$. This is usefully contrasted with the unit tax case, where - trivially - the elasticity of the tax base with respect to the capital stock is unity. So, we can write the elasticity of the tax base with respect to the tax rate as:

$$
\varepsilon_{a v}=-\left(\frac{t_{i}}{b_{i}} \frac{d b_{i}}{d t_{i}}\right)_{t_{1}=t_{2}=t}=-(1-\eta)\left(\frac{t_{i}}{k_{i}} \frac{d k_{i}}{d t_{i}}\right)_{t_{1}=t_{2}=t}
$$

Now, by direct calculation from (1), (3), as in the specific case, we get:

$$
-\left(\frac{t_{i}}{k_{i}} \frac{d k_{i}}{d t_{i}}\right)_{t_{1}=t_{2}=t}=\frac{1}{2}\left(\frac{t}{1-t}\right) \frac{1}{\eta}
$$

Comparing (5) and (7), note that when $t=T / f^{\prime}(k)$ i.e. the unit and ad valorem taxes are equal, then as long as $0<\mathrm{t}<1$, the elasticity of $k_{\mathrm{i}}$ with respect to the tax is greater in the ad valorem case than in the unit case. The intuition for this is as follows. Generally, when the tax (unit or ad valorem) rises in country $i$, the capital invested in that country falls, thus increasing the pre-tax rate of return, which compensates the investor for the rise in the tax. However, in the ad valorem

\footnotetext{
${ }^{5}$ Note that $\eta$ is an (inverse) measure of the elasticity of the tax base because when $f^{\prime \prime}$ is very small, i.e. the production function is almost linear, capital is very responsive to changes in the rate of return, and $1 / \eta$ is very large.
} 
case, the investor only keeps a fraction 1- $t_{i}$ of this increase in the pre-tax rate of return, whereas in the unit case, he keeps all of it. The implication is that following an increase in the tax of country $i$, the capital invested in country $i$ has to fall further in the ad valorem case, in order to maintain investor equilibrium.

Now, combining (6) and (7), we get our final formula for $\varepsilon_{\mathrm{av}}$ as:

$$
\varepsilon_{a v}=-\left(\frac{t_{i}}{b_{i}} \frac{d b_{i}}{d t_{i}}\right)_{t_{1}=t_{2}=t}=\frac{1}{2}\left(\frac{t}{1-t}\right)\left(\frac{1-\eta}{\eta}\right)
$$

Comparing (5) and (8), we see that when tax rates are equal, $\varepsilon_{\mathrm{av}}$ is greater or less than $\varepsilon_{\mathrm{u}}$ as $\mathrm{t}$ is greater or less than $\eta$. The reason, as explained above, is that there are two opposing changes when we move from unit to ad valorem taxation. First, as the tax base changes from $\mathrm{k}_{\mathrm{i}}$ to $f^{\prime}\left(k_{i}\right) k_{i}$, it becomes less responsive to a given change in $\mathrm{k}_{\mathrm{i}}$ itself. This is captured by the term 1$\eta$ and other things equal, reduces $\varepsilon_{\mathrm{av}}$. Second, following a given change in the tax rate, $\mathrm{k}_{\mathrm{i}}$ must fall by more to restore investor equilibrium. This is captured by the term 1-t and other things equal, increases $\varepsilon_{\mathrm{av}}$.

\section{Tax Competition}

We now turn to optimal tax setting. First, consider how the utilities of the residents of country i depend on the tax rates. The wage in country $\mathrm{i}$ is $w_{i}=f_{i}\left(k_{i}\right)-f_{i}^{\prime}\left(k_{i}\right) k_{i}$. As each resident of country i supplies one unit of labour, she has labour income of $\mathrm{w}_{\mathrm{i}}$. Each resident also has income from capital of her endowment $\mathrm{k}$ times the after-tax rate of return. So, total after-tax income, $y_{i}$ can be written:

$$
y_{i}=\left\{\begin{array}{lc}
f\left(k_{i}\right)-f^{\prime}\left(k_{i}\right) k_{i}+\left(f^{\prime}\left(k_{i}\right)-T_{i}\right) k & \text { (unit) } \\
f\left(k_{i}\right)-f^{\prime}\left(k_{i}\right) k_{i}+f^{\prime}\left(k_{i}\right)\left(1-t_{i}\right) k & (\text { ad valorem })
\end{array}\right.
$$

Residents of country $i$ have (indirect) utility functions defined on after-tax income $y_{i}$ and the supply of a public good, $\mathrm{g}_{\mathrm{i}}$. We will assume for simplicity that indirect utility is quasi-linear i.e.

$$
u_{i}=y_{i}+h\left(g_{i}\right)
$$


where $h($.$) is strictly increasing and strictly concave. Finally, the government budget constraint is$ standard i.e.

$$
g_{i}=\left\{\begin{array}{cc}
T_{i} k_{i} & (\text { unit }) \\
t_{i} b_{i} & (\text { ad valorem })
\end{array}\right.
$$

With tax competition in unit taxes, government 1 chooses $T_{1}$ to maximise $u_{1}$ given (9) and (11) and $\mathrm{T}_{2}$ constant, and government 2 does likewise. The first-order condition for choice of tax in country $i$ is

$$
\frac{\partial y_{i}}{\partial T_{i}}+h^{\prime}\left(g_{i}\right)\left(k_{i}+T_{i} \frac{\partial k_{i}}{\partial T_{i}}\right)=0
$$

With tax competition in ad valorem taxes, government 1 chooses $t_{1}$ to maximise $u_{1}$ given (9) and (11) and $t_{2}$ constant, and government 2 does likewise. The first-order condition for choice of tax in country $i$ is then

$$
\frac{\partial y_{i}}{\partial t_{i}}+h^{\prime}\left(g_{i}\right)\left(b_{i}+t_{i} \frac{\partial b_{i}}{\partial t_{i}}\right)=0
$$

Now from (9), in symmetric Nash equilibrium, when $\mathrm{k}_{\mathrm{i}}=\mathrm{k}$, we have:

$$
\frac{\partial y_{i}}{\partial T_{i}}=-k, \frac{\partial y_{i}}{\partial t_{i}}=-k\left[f^{\prime}(k)+t f^{\prime \prime}(k) \frac{\partial k_{i}}{\partial t_{i}}\right]
$$

in the unit and ad valorem cases respectively. Equation (14) says that in the unit case, a small increase in the tax rate decreases private income by the amount of the tax base. In the ad valorem case, we can rewrite the formula in (14) describing the impact of an increase in the tax rate on private income as:

$$
\frac{\partial y_{i}}{\partial t_{i}}=-b\left[1-\eta\left(\frac{t_{i}}{k_{i}} \frac{d k_{i}}{d t_{i}}\right)_{t_{1}=t_{2}=t}\right\rceil=-b\left[1+\frac{\eta}{1-\eta} \varepsilon_{a v}\right]
$$


This describes the impact of an increase in the tax rate on private income in the ad valorem case. We see that when ${ }^{6} \eta<1$, a small increase in the tax rate decreases private income by an amount more than the tax base. The reason for the latter is that with ad valorem taxes, there is a positive, as well as negative, effect of the tax rate on the tax base: when $t_{i}$ rises, $k_{i}$ falls (reducing the tax base) but the rate of return $f^{\prime}\left(k_{i}\right)$ rises, increasing the tax base. Call this the rate of return effect.

Evaluating the first-order conditions (12),(13) at symmetric equilibrium, using (15), and rearranging in elasticity form, we get:

$$
\begin{aligned}
& -1+h^{\prime}\left(g_{u}\right)\left[1-\varepsilon_{u}\right]=0 \\
& -1-\frac{\eta}{1-\eta} \varepsilon_{a v}+h^{\prime}\left(g_{a v}\right)\left[1-\varepsilon_{a v}\right]=0
\end{aligned}
$$

in the unit and ad valorem cases respectively, where $\mathrm{g}_{\mathrm{u}}, \mathrm{g}_{\mathrm{av}}$ denote the levels of public good provision in each country with unit and ad valorem taxation respectively. Note that in each case, $h^{\prime}(g)$ is the marginal benefit of public funds. So these conditions (16),(17) can be written in the more usual form that the marginal benefit of public funds is equal to the marginal cost of public funds:

$$
h^{\prime}\left(g_{u}\right)=\frac{1}{1-\varepsilon_{u}}, \quad h^{\prime}\left(g_{a v}\right)=\frac{1+\left(\frac{\eta}{1-\eta}\right) \varepsilon_{a v}}{1-\varepsilon_{a v}}
$$

In each case, the right-hand side is the marginal cost of public funds (MCPF). It is clear that there are two differences between the MCPF in the unit and ad valorem cases: (i) different tax base elasticities, (ii) in the ad valorem case, the additional term in the numerator reflects the rate of return effect on private utility.

These equations (18) can be contrasted with the first-best, where the public good would be financed out of a lump-sum tax on the fixed factor, labour. In this case, the MCPF is unity, and

\footnotetext{
${ }^{6}$ In the case where $\mathrm{F}$ is Cobb-D ouglas, which is our central case of interest, it can be shown that $\eta<1$ : see the proof of
} 
so, assuming an interior solution, first-best public good supply $\mathrm{g}^{*}$ satisfies $h^{\prime}\left(g^{*}\right)=1$. We will assume that $h^{\prime}(0)>1$ so that the solution is indeed interior i.e. $\mathrm{g}^{*}>0$. In this case, as $\varepsilon_{\mathrm{u}}<0$ whenever T>0, with unit taxation, the MCPF is greater than unity, so $h^{\prime}\left(g_{u}\right)>1$, implying the well-known result that the public good is undersupplied in Nash equilibrium $\left(g_{u}<g^{*}\right)$. In the ad valorem case, as $\varepsilon_{\mathrm{av}}<0$ whenever $\mathrm{T}>0$, we have a similar result.

However, To make any kind of global comparison between the MCPFs, or between public good supplies, in Nash equilibrium, we must assume that $\eta$ is constant, which requires that the production function is Cobb-Douglas. Then, we have:

Proposition 1. Assume that $F(K, L)$ is Cobb-Douglas.. Then, in Nash tax equilibrium, public good supply is always lower with an ad valorem tax than with a unit tax $\left(g_{a v}<g_{u}\right)$. Consequently, the equilibrium ad valorem equivalent of the equilibrium unit tax, $T / f^{\prime}(k)$, is always higher than the equilibrium ad valorem tax i.e. $t<T / f^{\prime}(k)$.

Proof. By assumption, $F=K^{\alpha} L^{1-\alpha}$, for some $0<\alpha<1$. Then, by direct calculation, $\eta=1-\alpha$ so we can take $\eta$ as a constant between zero and one. Then it is easy to check that in each case, the MCPF is increasing in the tax rate. So, to prove the result, is sufficient to show that when tax rates are the same i.e. when $t=T / f^{\prime}(k)$, the MCPF is higher in the ad valorem case. By substitution of (5) into (18), the MCPF in the unit tax case is

$$
\mathrm{MCPF}_{\mathrm{u}}=\frac{1}{1-0.5 \frac{t}{\eta}}
$$

Also, by substitution of (8) into (18), the MCPF in the ad valorem tax case is

$$
\mathrm{MCPF}_{\mathrm{av}}=\frac{1+0.5\left(\frac{t}{1-t}\right)}{1-0.5\left(\frac{1-\eta}{\eta}\right)\left(\frac{t}{1-t}\right)}
$$

Proposition 1 below. 
After some rearrangement, we get

$$
\mathrm{MCPF}_{\mathrm{av}}=\frac{1}{1-0.5\left(\frac{t}{\eta}\right) /(1-0.5 t)}>\frac{1}{1-0.5 \frac{t}{\eta}}=\mathrm{MCPF}_{\mathrm{u}}
$$

as required, as $t \leq 1$. But So, we have proved that $g_{u}>g_{a v}$. But then from (11), we require that $T k>t b=t k f^{\prime}(k)$, so the result follows.

This result is illustrated below. The Figure shows both the MCPF with lump-sum taxation (constant at unity), $\mathrm{MCPF}_{\mathrm{s}}$, and $\mathrm{MCPF}_{\mathrm{av}}$, and the associated levels of public good supply.

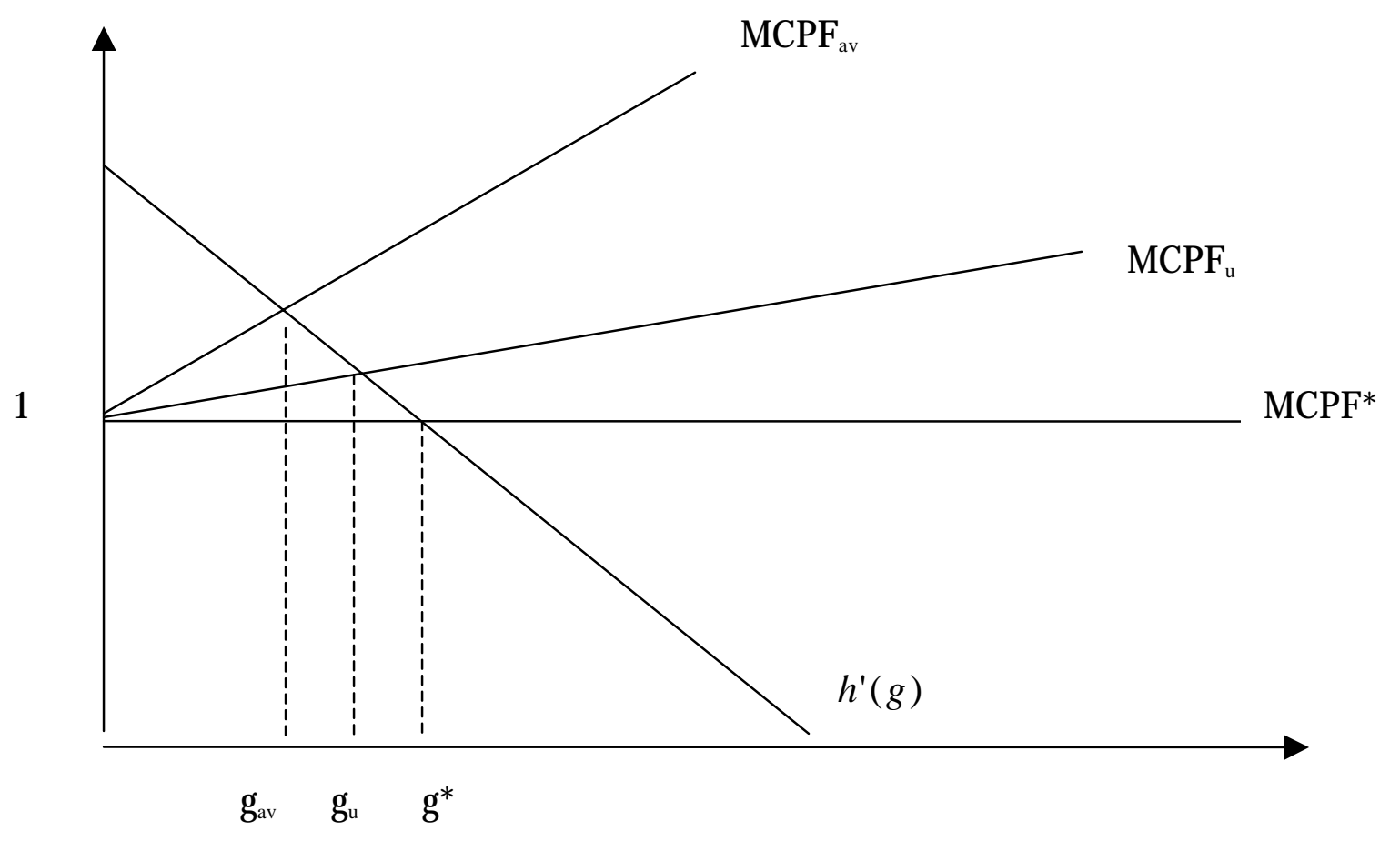

Now we turn to welfare comparisons. Let $\mathrm{u}_{\mathrm{u}}, \mathrm{u}_{\mathrm{av}}$ be the payoffs to residents of each country in Nash tax equilibrium with unit and ad valorem taxes respectively. Then we have:

Proposition 2. Assume that $F$ is Cobb-Douglas. Then, given that taxes are set non-cooperatively, all agents prefer unit taxes to ad valorem taxes i.e. $u_{u}>u_{\mathrm{av}}$. 
Proof. From the definition of $u_{i}$, using (9), (11), we see that at the symmetric Nash equilibrium in taxes, the payoff to any agent is $u(g)=f(k)-g+u(g)$. This expression is a concave function of $g$ with a maximum at $g^{*}$, the first-best level of the public good. As argued above, $g_{a v}<g_{u}<g^{*}$, so the result follows immediately.

\section{Conclusions}

We have shown in this paper that in tax competition, it matters whether taxes on capital income are specific or ad valorem. This conclusion will also carry over to other forms of tax competition (e.g. in commodity taxes), although the specific results may not. The main issue raised by our analysis is that unit taxes on the number of units of capital invested are preferred to ad valorem taxes on capital income. In practice, only ad valorem taxes are observed. 


\section{References}

S. Bucovetsky (1991) “Asymmetric tax competition”, Journal of Urban Economics 30, 67-81

S.Delipalla and M.Keen (1992) "The comparison between ad valorem and specific taxation under imperfect competition" Journal of Public Economics 28, 127-134

B.Lockwood and K.Wong (2000) "“'Specific and Ad Valorem Tariffs are not Equivalent in Trade Wars", Journal of International Economics, 52, 183-95

B.Lockwood (2001) "Tax competition and coordination with destination and origin principles: a synthesis", Journal of Public Economics, 81, 279-319

S.E.Skeath and G.A. Trandel (1994) "A Pareto comparison of ad valorem and unit taxes in noncompetitive environments", Journal of Public Economics, 53, 53-71

D.B.Suits and R.A..Musgrave(1953), “Ad valorem and unit taxes compared”, Quarterly Journal of Economics 67, 598-604

J.D.Wilson(1986) "A theory of interregional tax competition" Journal of Urban Economics, 19, 296-315

J.D.Wilson (1999) “Theories of tax competition” National tax Journal, 52, 269-304

K.Wicksell(1959) "Taxation in the monopoly case", translated and reprinted in: Musgrave and Shoup, eds, Readings in the Economics of Taxation (Irwin, Homewood, IL) 